\title{
Arteriographic Assessment of Placental Vascularity after Antepartum Haemorrhage
}

\author{
J. G. HILL, ${ }^{*}$ M.B., F.R.C.S.GLASG., M.R.C.O.G. ; F. J. BRUNTON, † M.B., M.R.C.P., F.F.R.
}

[With Special Plate facing Page 28]

Brit. med. F., 1968, 2, 25-26

During the last decade there has been a gradual shift of emphasis in the management of antepartum haemorrhage. Placenta praevia, dangerous as it may be, presents fewer problems of management since the adoption of conservative therapy and the increased use of caesarean section as advocated by Macafee (1945). Stallworthy (1951) declared that in the management of placenta praevia our aim should be a maternal mortality of nil and a foetal mortality of less than $10 \%$, and these figures have now been achieved in most modern departments.

However, in many cases of antepartum haemorrhage no cause is found for the bleeding, and the foetal wastage in this group of "unclassified haemorrhage" is still high. Different writers put the mortality in this group between 10 and $27 \%$. The high mortality is presumably due to circulatory inadequacy of the placenta after separation of a portion of its surface. As bed rest is known to increase the uterine blood flow (Morris et al., 1956), there are grounds for detaining in hospital until delivery all patients who have had an antepartum haemorrhage irrespective of the situation of the placenta. Such a policy would be expected to increase the foetal salvage but has not been generally accepted, as it results in a large number of women being unnecessarily detained in hospital for many weeks. From the foetal mortality figures we can assume that in only a minority of cases is the placental circulation dangerously reduced. The problem is to recognize the cases at risk.

If information could be obtained about the effective circulation of the placenta after the occurrence of haemorrhage it should not be difficult to pick out these cases-that is, those in which the placental vascularity is considerably diminished. Brink (1960) observed that arteriography is not only useful in locating the placenta but can also give an assessment of its vascularity. He suggested that it is possible to recognize a deficiency in sinusoids as an indication of inadequate placental circulation.

Location of the placental site by arteriography was begun in Southampton in July 1965. In September of that year the following case was investigated and the outcome prompted us to think along the lines suggested by Brink.

A primigravida aged 23 was admitted to hospital at 32 weeks' gestation after a slight, painless antepartum haemorrhage. Arteriography was carried out and only two sinusoids were demonstrated. The small number of sinusoids was thought to be due to a technical fault, and as there was no radiographic evidence of placenta praevia the patient was allowed to go home. Two weeks later the foetal heart was heard but the uterus was noted to be small for dates. One week later, at the 35th week, she was admitted in labour and the foetal heart could not be heard. A macerated stillborn infant weighing $2 \mathrm{lb}$. $5 \mathrm{oz}$. $(1,050 \mathrm{~g}$.) was delivered and the placenta showed evidence of previous separation and old retroplacental haemorrhage.

- Senior Registrar, Department of Obstetrics, Southampton General Hospital. Present address: Department of Obstetrics, St. George's

Hospital, London S. W.1.
t Consultant Radiologist, Southampton General Hospital. Present address: Department of Obstetrics, St. George's Hospital, London S.W.1.
This case bore a remarkable similarity to the one described by Brink in which only a few sinusoids were shown and the foetus died in utero some weeks later. In both these cases it is assumed that the haemorrhage had separated so much of the placental surflace that the circulation to the foetus was greatly reduced; with the continuation of the pregnancy this circulation became ultimately inadequate and the foetus died.

It was decided, therefore, to continue investigating all caseo of antepartum haemorrhage by arteriography and to carry out a prospective survey of the placental vascularity.

\section{Material and Methods}

Fifty-eight patients were investigated by arteriography between September 1965 and February 1967. During this time the total number of deliveries in the area was 9,500 . All patients with an antepartum haemorrhage before the 35 th week, excluding cases of abruptio placentae and premature labour, were examined by arteriography. The procedure was also carried out after the 35th week in four cases in which there was also a malpresentation. No other method of placentography was used. Arteriography was performed as early as the 27 th week of pregnancy in three patients, and the average for the series was $31 \frac{1}{2}$ weeks. The examination was not carried out until bleeding had ceased for at least four days.

Patients diagnosed radiographically as having a placenta praevia were detained in hospital and managed in the usual manner.

All the other patients were allowed home and were non readmitted unless further obstetric complications arose. It was decided not to induce labour routinely at the 38th week in these cases as the significance of the radiographic assessment of the placental vascularity was not known. The pregnancy was allowed to continue until 42 weeks unless there was some other obstetric complication. In seven patients labour was induced before term. In three of these there was an associated preeclampsia, and in four there was further haemorrhage.

\section{Technique}

The procedure is carried out under sedation and local anaesthesia. The catheterization is by the standard Seldinger method and is similar to that advocated by Sutton (1966). The Seldinger-Sutton needle, the fine guide wire (both size P.E. 160), but the larger polyethylene catheter (size P.E. 240) are used The catheter, which has a tapered tip and at least two side holes, is introduced about $25 \mathrm{~cm}$. so that it reaches just above the aortic bifurcation. The contrast used is Conray 420 (sodium isothalamate), $25 \mathrm{ml}$., and is injected forcibly by hand. A single film is taken two and a half seconds after the completion of the injection. There is some variation of the flow rate, and occasionally the film has had to be repeated, usually after a longer time interval. A position 5 degrees from the true lateral has been found to be best for assessing the position of 
the placenta (Special Plate, Fig. 1). Earlier in our investigation some patients were examined in the anteroposterior and/or oblique position.

Cervical Marker.-With a Sims speculum a $50-\mathrm{mm}$. contraceptive cap is gently placed over the cervix. The metal spring in the rim is thus in close proximity to the internal os (Special Plate, Fig. 1). We consider this form of marking superior to other methods and of great help in placental location.

Complications.-The patients require reassurance, but tolerate the examination extremely well. We have encountered no serious complications. After an uneventful placentogram, one patient complained of a painful area on the outer aspect of the hip some days later, which necessitated readmission to hospital. The area was well away from the skin puncture and her symptoms gradually regressed over two to three weeks.

Film Interpretation.-If the lowermost sinus was within $10 \mathrm{~cm}$. of the cervical marker the placenta was considered to be praevia and these patients were kept in hospital. We have been particularly interested in the films showing the placentae in the upper segment, and in these we have studied the sinusoids carefully. No attempt was made to grade the degree of filling, but from the appearance of the sinusoids the vascularity was considered to be either adequate or deficient. Exact enumeration was found to be impracticable owing to the frequency with which the sinusoids appeared to be confluent. In practice little difficulty was experienced in deciding whether the filling of the sinusoids was adequate or not. A technical problem in assessing placental vascularity has been the individual variation in circulation time. For this reason a second film has sometimes been required, but with increasing experience this has become less frequent.

\section{Results}

From a total of 58 patients in the series there were 60 births. There were two stillbirths and no neonatal deaths, giving a perinatal mortality of $3.3 \%$. There were no maternal deaths.

Of the 58 cases investigated the placenta was found to encroach on the lower segment in 10 . This study concerns the remaining 48. Forty-four of these patients had a wellvascularized placenta, the foetal mortality being nil. The remaining four were thought to have a poorly vascularized placenta, and in this group there was one foetal death.

A gravida- 2 aged 27 had slight painless antepartum haemorrhage at 29 weeks. The placentogram showed a very poorly vascularized placenta in the upper segment (Special Plate, Fig. 2). As there was no evidence of placenta praevia the patient was allowed home. She had a further slight bleed at home at 33 weeks and was then readmitted in premature labour. The foetal heart could not be heard. A fresh stillborn infant weighing $2 \mathrm{lb}$. $(910 \mathrm{~g}$.) was delivered after six hours of labour. The placenta weighed $348 \mathrm{~g}$. (12 oz.) and was grossly infarcted (Special Plate, Fig. 3).

In the three other patients in whom the vascularity was thought to be deficient the pregnancies resulted in live births and the placentae showed no gross abnormalities. The average weight of these three infants was $6 \mathrm{lb} .10 \mathrm{oz}$. $(3,020 \mathrm{~g}$.) and the average duration of pregnancy at delivery was $39 \frac{1}{2}$ weeks.

\section{Discussion}

It is accepted that placentography is a reliable method of placental location. It is desirable to find out whether further relevant information can be obtained from the films. This would include the diagnosis of placental insufficiency. An attempt has been made in this series to assess the vascularity of the placenta and to correlate this with the subsequent course of the pregnancy. It had been hoped that it would be possible to determine those cases most at risk so that they could be treated by bed rest.

In four of our patients the placental circulation was regarded as inadequate, but in three of them this was not confirmed by the outcome of the pregnancy, and the placentae showed no structural abnormality. It is perhaps noteworthy that these three occurred among the first 12 in the series, and at that time the examination was less satisfactory technically.

Having reviewed these films, we now believe that our original assessment was inaccurate, and that the evidence was unconvincing.

There was, however, no doubt about the poor filling in our fourth case (Special Plate, Fig. 2). This patient had a fresh stillbirth three weeks later and the placenta showed numerous infarcts. The findings and outcome were similar in one earlier case, though the significance of the arteriographic findings was not appreciated at the time. The series was conducted to assess the frequency and significance of poor sinus filling. We consider that this appearance of diminished vascularity merits further observation.

\section{Summary}

Arteriographic placentography is already an accepted method of placental location in some centres. Two cases have been encountered where the placental sinus filling was poor at placentography and in both instances the foetus was born dead. Our experience suggests that diminished vascularity may be a sign of placental insufficiency.

We would like to thank Mr. R. W. Knowlton and Mr. D. R. Kilgour for allowing us to conduct this series, and for their constructive criticism. We are also indebted to Miss D. Claisse for radiographic assistance and to Miss I. J. Underhill of the photographic department, St. George's Hospital, for the illustrations.

\section{REFERENCES}

Brink, D. (1960). 7. Obstet. Gynaec. Brit. Emp., 67, 437. Brink, D. (1960). (1945) \% Obstet. Gynaec. Brit. Emp. 52, 313 Morris, N., Osborn, S. B., Payling-Wright, H., and Hart, A. (1956). Lancet, 2, 481

Stallworthy, J. (1951). Amer. 7. Obstet. Gynec., 61, 720.

Sutton, D. (1966). Brit. F. Radiol., 39, 47. 
J. G. HILL AND F. J. BRUNTON: ARTERIOGRAPHIC ASSESSMENT OF PLACENTAL VASCULARITY

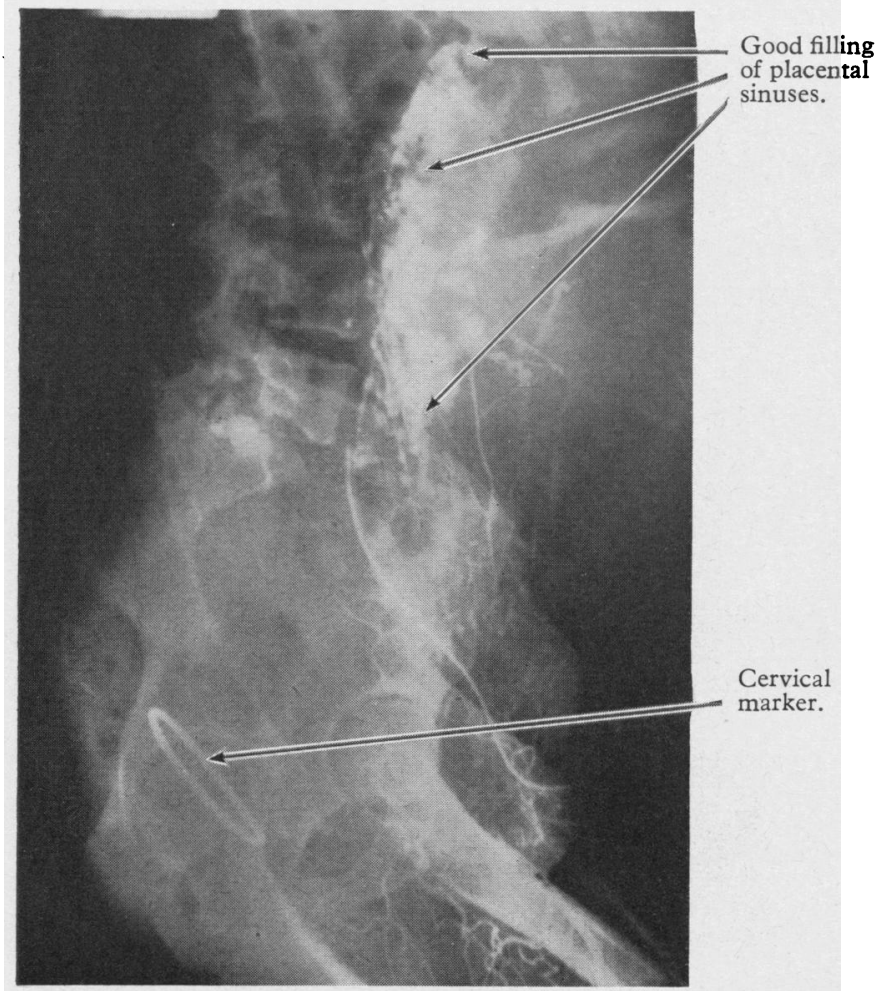

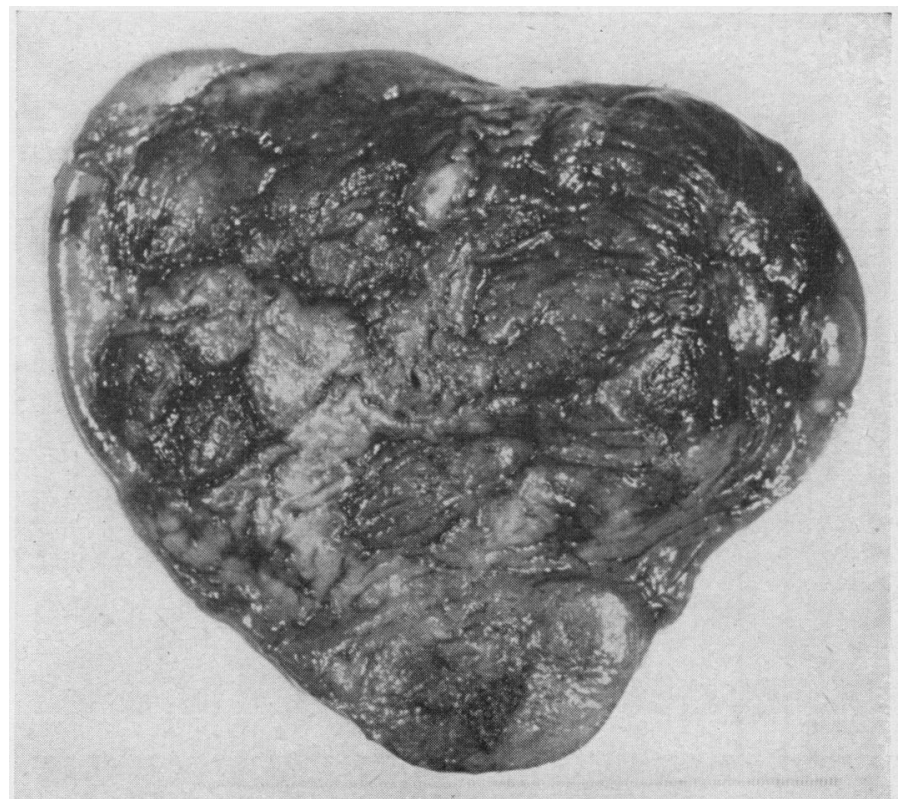

Fig. 3.-Placenta from case illustrated in Fig. 2, showing numerous infarcts indicated by pale areas.

K. WHALEY AND W. CARSON DICK: FATAL SUBAXIAL DISLOCATION OF CERVICAL SPINE

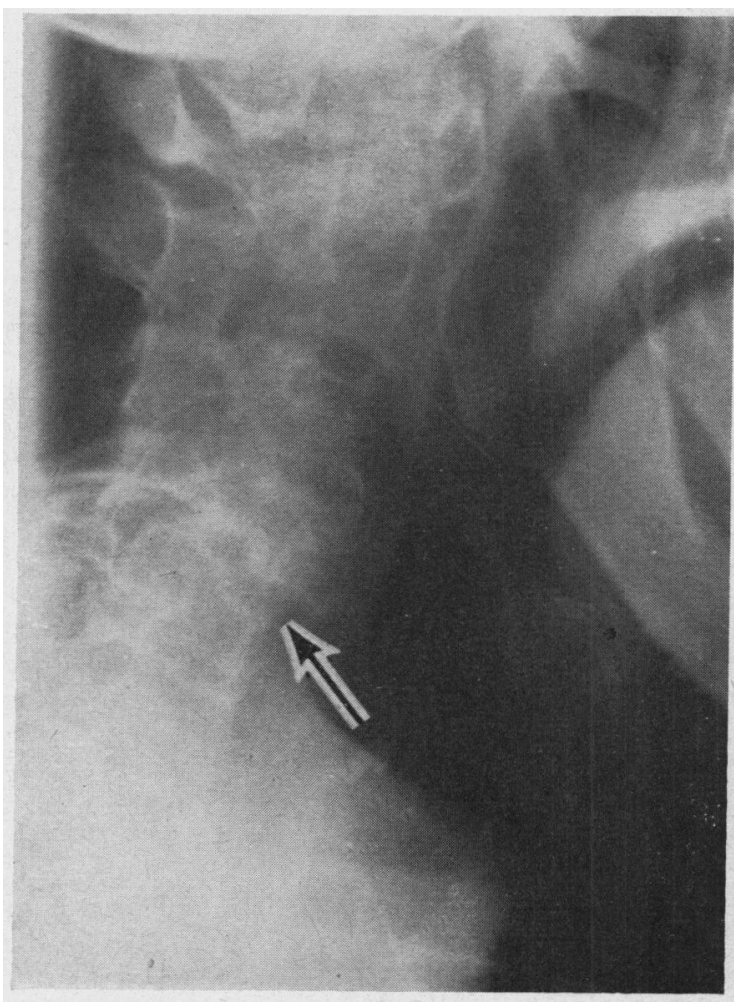

FIG. 1.- X-ray film showing forward subluxation of the body of the fourth on the fifth cervical vertebra (arrowed). The atlanto-axial- joint is seen to be normal. 